\title{
Basketbolcularda Core Alt Ekstremite Kuvveti Antrenmanlarının Dinamik Denge ve Şut İsabeti Üzerine Etkisi
}

\author{
Oğuzhan YÜKSEL \\ Yağmur AKKOYUNLU* \\ M. Barış KARAVELIOĞGLU* \\ Halit HARMANCI ${ }^{* * * *}$ \\ Mert KAYHAN ${ }^{* * * * *}$ \\ Harun $\mathrm{KOÇ}^{* * * * * *}$
}

\section{Öz}

Bu çalışmanın amacı erkek basketbolcuların Core antrenmanlarının denge ve şut isabet değerleri üzerine etkisinin belirlenmesidir. Bu çalışmaya erkek basketbolculardan sporculardan 18 yaş ve üzeri takım sporuyla uğraşan 30 gönüllü katılımcı (15 kontrol, 15 deney) yer almıștır. Deney grubunda yer alan katılımcıların boy değerleri $(\mathrm{n}=15)$ 190,3 $\pm 8,17 \mathrm{~cm}$, vücut ağırlığı $(\mathrm{n}=15) 88,3 \pm 8,13 \mathrm{~kg}$; kontrol grubunda ise $(\mathrm{n}=15) \quad 190,86 \pm 8,97 \mathrm{~cm}$, vücut ağırlığ $(\mathrm{n}=15) 88,8 \pm 11,99 \mathrm{~kg}$ olarak tespit edilmiştir. Deney grubundaki katılımcilar sekiz hafta boyunca Core antrenman programı uygularken kontrol grubunda ise herhangi bir antrenman program yapılmamıştır. Katılımcılardan Yıldız Uzan Eriş Denge Testi (Star Excursion Balance Test) (YUEDT) sonuçları ve 60 saniye süre içerisinde iki ve üç sayı isabet skorları kayıt altına alınmıştır. Yıldız Uzan Eriş Denge Testi (Star Excursion Balance Test) (YUEDT) ve 60 saniye süre içerisinde iki ve üç sayı isabet skorlarının yüzdeleri için iki yönlü varyans analizi (twoway repeated measures of ANOVA) yapıldı. Yıldız uzan eriş denge (YUEDT) ön-son test dereceleri sonucunda; sol alt ekstremitede lateral, posteriolateral, posteriormedial, medial, anteromedial değerlerinde ve sağ alt ekstremitede ise posteriolateral, posterior, posteromedial ve medial değerlerinde grupXzaman etkileşiminde etkin artış görülmektedir $(\mathrm{p}<0,05)$. Bir dakikalık iki sayılık ve üç sayılık şut isabet yüzdelerinde ön-test sonucunda grupXzaman etkileşiminde anlamlı artış meydana gelmiştir $(\mathrm{p}<0,05)$.

Anahtar kelimeler: Denge, Basketbol, Core Antrenman

\footnotetext{
* Yrd. Doç. Dr., Dumlupınar Üniversitesi, Beden Eğitimi ve Spor Yüksekokulu, oguzhan.yuksel@dpu.edu.tr

** Doç. Dr., Dumlupınar Üniversitesi, Beden Eğitimi ve Spor Yüksekokulu, yagmur.akkoyunlu@dpu.edu.tr

*** Doç. Dr., Dumlupınar Üniversitesi, Beden Eğitimi ve Spor Yüksekokulu, mbaris.karavelioglu@dpu.edu.tr

**** Yrd. Doç. Dr., Dumlupınar Üniversitesi, Beden Eğitimi ve Spor Yüksekokulu, halit.harmanci@dpu.edu.tr

***** Arş. Gör., Dumlupınar Üniversitesi, Beden Eğitimi ve Spor Yüksekokulu, mert.kayhan@dpu.edu.tr

***** Arş. Gör., Dumlupınar Üniversitesi, Beden Eğitimi ve Spor Yüksekokulu, hakoc@dpu.edu.tr
} 


\title{
The effects of Core Strenght Training on Balance and Shot Percantage on Male Basketball Players
}

\begin{abstract}
The purpose of this study was to determine effect of core strenght training on balance and shot percantage on male basketball players. 30 male basketball players (15 test, 15 control) which at least 18 years old participated voluntarily in the study. The test group participants mean of body height ( $\mathrm{n}=15) 190,3 \pm 8,17 \mathrm{~cm}$ and mean of body weight $88,3 \pm 8,13 \mathrm{~kg}$, the control group participants mean of body height ( $\mathrm{n}=15) 190,86 \pm 8,97 \mathrm{~cm}$ and mean of body weight $88,8 \pm 11,99 \mathrm{~kg}$. While the test group trained for eight week with core training and dinamic leg strenght, the control group were not trained. Athletes Star Excursion Balance Test values and shot scores were recorded for 2 point and 3 point areas in sixty seconds. Two-way repeated measures of ANOVA was used for Star Excursion Balance Test and shot test for 2 point and 3 point areas in sixty seconds. Significant differences were found in group $\times$ time interaction during Star Excursion Balance first and last tests on left lower extremity on lateral, posteriolateral, posteriormedial, medial, anteromedial and right lower extremity posteriolateral, posterior, posteromedial ve medial $(\mathrm{p}<0,05)$. Significant differences were found before and after shot tests from two point and three point area in group $\times$ time interaction $(\mathrm{p}<0,05)$.
\end{abstract}

Keywords: Balance, Basketball, Core Training

\section{GíRiş}

Denge özelliği basketbol için en önemli koordinasyon yeteneklerinden biridir (Kostopoulos, Bekris, Apostolidis, Kavroulakis ve Kostopoulos, 2012). Within the field of athletic training, neuromuscular training programs that include balance exercises are often implemented with the aim of optimizing performance, preventing injury, or providing rehabilitation (Zech ve ark.,2010). Denge özellikle vücudun ağırlık merkezinin değişmesi nedeniyle oluşan değişime karşı çözüm üreten bir yetidir ve görsel, vestibülar ve somatik hislerin geri bildirimi yoluyla sinir kas uyarısının bir sonucudur (Boccolini, Brazzit, Bonfanti ve Alberti, 2013). Denge statik ve dinamik olmak üzere ikiye ayrılmaktadır. Statik denge, vücudun dengesini belli bir yerde ya da pozisyonda sağlama yeteneği iken, dinamik denge ise hareket halinde vücudun bütünü ya da bir kısmının dengesini sağlama yeteneğidir (Kuşakoğlu,2012). Dengeyi kontrol etmek ve bu kontrolü sürdürebilmek basketbol branşından mükemmelleşebilmek için oldukça gereklidir (Kaushik ve Sharma, 2013).

Core kavramı sternum ve dizler arasında kalan, abdominal bölge, bel ve kalçaları kapsayan kısım olarak ele alınmaktadır (Santana,2005). Bireyin kendi vücut ağırlığı ile gerçekleştirdiği, omurgayı dengede tutmakta olan derin kasların ve lumbo pelvik bölgede yer alan kaslarının kuvvetlendirilmesini amaçlayan egzersiz programına core antrenman denmektedir (Atan, 
Kabadayı, Elioz, Cilhoroz ve Akyol, 2013). Core denge egzersizleri medikal rehabilitasyon, antrenman, sağlı gibi birçok farklı alanda kullanılmaktadır. Bu egzersiz çeşidi dinamik denge, fonksiyonel anatomi, statik denge ve esneklik özelliklerini geliştirmektedir (Xibo, Qian, Honglei ve Shujie, 2016). Çünkü core antrenmanlar hem kaslarda yapısal değişime hem de nöral adaptasyona neden olmaktadır (Iacono, Martone, Alfieri, Ayalon ve Buono, 2014). Ayrıca dinamik ve statik antrenman olarak kullanılan core egzersizler proprioreseptif duyuları geliştirip kassal iyileşme ve vücut kontrolü sağlayarak core dengeyi ve kuvveti geliştirir (Hibbs, Thompson, French, Hodgson ve Spears, 2011).

\section{YÖNTEM}

Bu çalışmada branşı basketbol olan 18 yaş ve üzeri 30 gönüllü erkek katılımcı (15 kontrol, 15 deney) yer almıştır. Ölçümlerden bir gün önce katılımcılar test hakkında bilgilendirildi. Katılımcılara uygulanan testlerin sağlık açısından herhangi bir sakıncasının bulunmadığına dair bilgi verildi.

Basketbolcuların dinamik denge performanslarını belirleyebilmek için Yıldız Uzan Eriş Denge Testi (YUEDT) kullanıldı. YUEDT uygulamasında, bireyin destek ayağıyla vücut sabitliğini koruması ve diğer ayağıyla ise farklı yönlere maksimum uzanıp ilk pozisyonuna geri dönmesini gerektirmektedir. Katılımcıya uzanabileceği en son noktada sekiz farklı yöndeki çizgilere (anterior, posterior, medial, lateral, anterior medial, anterior lateral, posterior medial ve posterior lateral) uzanması istendi. Test sırasında katılımcının uzanma noktasına hafif dokunuş yaparak diğer ayağın pozisyonunu bozmadan merkezdeki başlangıç pozisyonuna geri dönmesi sağlandı. Maksimum uzanma mesafesi, uzanma ayağının en son noktada eriştiği mesafe olarak tespit edildi. Deneme katılımcı destek ayağını yerden kaldırırsa, merkez noktadan uzaklaştırırsa ve uzanma ayağı uzandığı noktaya dokunma yerine destek alacak şekilde basarsa kabul edilmeyerek ve tekrar uygulama yapılması sağlandı. YUEDT ile her katılımcıya iki ayağıyla da 8 çizgide 3 deneme hakkı tanındı. Her denek testin başlangıcında sağ ayak merkezde olacak şekilde teste başladı. 3 deneme sonunda 5 dakika ara verilerek diğer ayakla 3 deneme daha uygulanması sağlandı (Gribble, Hertel ve Plisky,2012).

İki Sayılık Şut İsabet Testi ile oyuncuların 2 sayı performansları ölçüldü. Oyuncu 1 numaralı huniden 2 numaralı huniye doğru koştu ve P1 noktasından pası alarak 2 numaralı huninin hizasından şut attı. Şutu atar atmaz 1 numaralı huniye doğru kat etti devamında 1 numaralı huninin etrafından dönerek 3 numaralı huniye doğru koştu. 3 numaralı huninin etrafından dolaşarak P1 noktasından pası aldı. Pas sonrası topu alır almaz 3 numaralı huninin hizasından şut attı. Bu prosedür 4., 5. ve 6. hunilerde de aynen uygulandı. 60 saniye içerisinde belirlenen parkuru tamamlaması istendi. 60 saniye içerisinde kullanılan şuttan sayı olanlar kaydedildi. 3 kez test uygulandı. Testler arasında tam dinlenme uygulandı. Her katılımcıya deneyin prosedürü hakkında genel geçer bilgiler sunuldu (Pojskić, Šeparović ve Užičanin, 2011). 


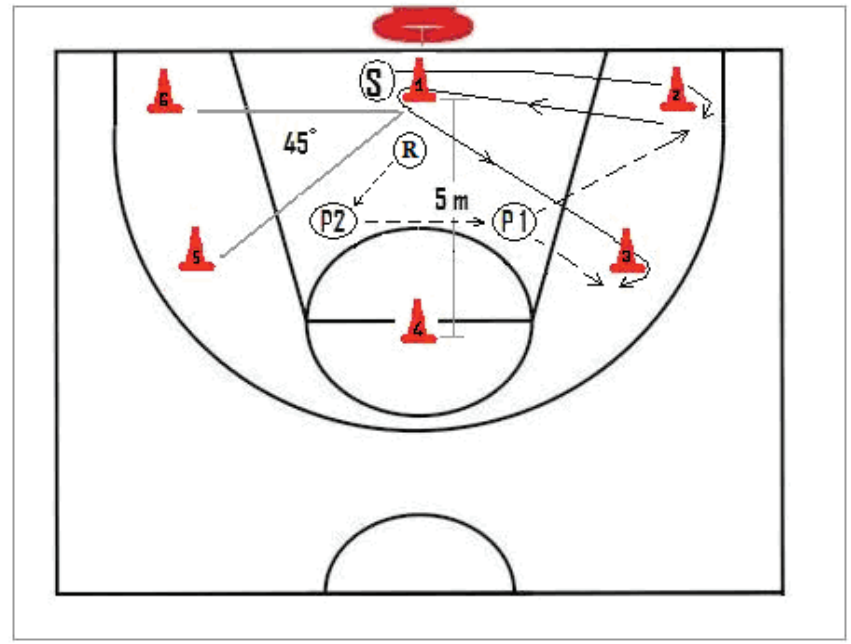

Şekil I. İki Sayılık Şut İsabet Testi

Üç Sayılık Şut İsabet Testi ile oyuncuların 3 sayı performansları ölçüldü. Oyuncu 1 numaralı huniden 2 numaralı huniye doğru koştu ve P1 noktasından pası alarak 2 numaralı huninin hizasından şut attı. Şutu atar atmaz 1 numaralı huniye doğru kat etti devamında 1 numaralı huninin etrafından dönerek 3 numaralı huniye doğru koştu. 3 numaralı huninin etrafından dolaşarak P1 noktasından pası aldı. Pas sonrası topu alır almaz 3 numaralı huninin hizasından şut attı. Bu prosedür 4., 5. ve 6. hunilerde de aynen uygulandı. 60 saniye içerisinde belirlenen parkuru tamamlaması istendi. 60 saniye içerisinde kullanılan şuttan sayı olanlar kaydedildi. 3 kez test uygulandı. Testler arasında tam dinlenme uygulandı. Her katılımcıya deneyin prosedürü hakkında genel geçer bilgiler sunuldu (Pojskić ve ark., 2011).

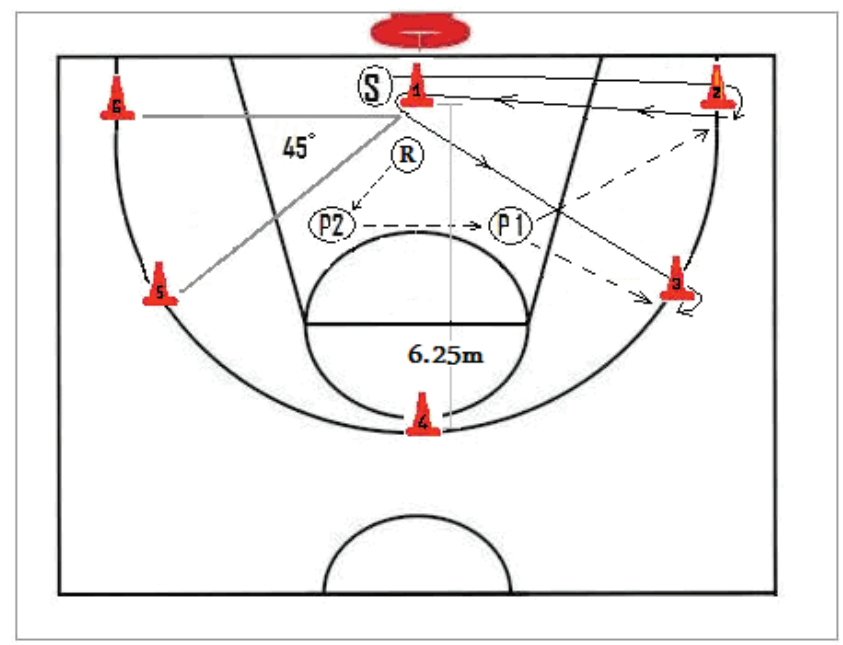

Şekil 2. Üç Sayılık Şut İsabet Testi 
Kontrol ve deney grubunda yer alan gönüllü katılımcıların şut skor ve yıldız uzan eriş denge testi ilk değerleri alındıktan sonra deney grubuna core antrenmanlar haftada 3 gün olmak kaydıyla 8 hafta boyunca program dâhilinde uygulandı. Kontrol grubu ise herhangi bir antrenman programina dâhil olmadi.

Uygulanan antrenman programı tablo 1'de tanımlandığı gibi core antrenman (CA) olarak adlandırilan antrenman metodudur. 8 hafta süreyle devam eden CA haftada 3 gün olacak şekilde uygulandı. 8 farklı hareket formunu içeren antrenman programında setler arası 2 dakika dinlenme uygulanmıștır (Kahle ve Tevald, 2014).

Tablo I. Antrenman detayları (Kahle ve Tevald, 20I4).

\begin{tabular}{|c|c|}
\hline Hareketler & İçerik \\
\hline Köprü & $\begin{array}{l}\text { Köprü pozisyonunda } 5 \text { saniye statik duruş ve sonrasında alçalma. } 10 \text { tekrar şeklinde } \\
\text { yapilır. }\end{array}$ \\
\hline $\begin{array}{l}\text { Gövde } \\
\text { Ekstansiyon }\end{array}$ & $\begin{array}{l}\text { Dizler bükülü vaziyette yere oturulur ve kollar öne kaldırılır. } 45 \text { derecelik açı yapacak } \\
\text { şekilde geriye doğru yatılır ve } 15 \text { saniye beklenip başlangıç pozisyonuna gelinir. }\end{array}$ \\
\hline Mekik & $\begin{array}{l}\text { Kafa ve omuzlar yukarı doğru kaldırılıp } 5 \text { saniye statik sonrası ilk pozisyona dönülür. } 10 \\
\text { tekrar șeklinde devam edilir. }\end{array}$ \\
\hline $\begin{array}{l}\text { Romen } \\
\text { Sehpasinda } \\
\text { Mekik }\end{array}$ & $\begin{array}{l}\text { Romen sehpasında dizler bükülü, eller çapraz şekilde göğüs kafesine yerleştirilerek mekik } \\
\text { pozisyonunda } 5 \text { saniye statik duruş sonrası tekrar başlangıç pozisyonuna dönülür. } 10 \\
\text { tekrarlı uygulanır. }\end{array}$ \\
\hline $\begin{array}{l}\text { Abdominal } \\
\text { kasilma }\end{array}$ & $\begin{array}{l}\text { Dizler bükülü, eller çapraz göğüs kafesinde nefes alıp verme sırasında karın kaslarının } 5 \\
\text { saniye kasılıp tekrar gevşetilmesi. } 10 \text { tekrarlı uygulanır. }\end{array}$ \\
\hline $\begin{array}{l}\text { Alt } \\
\text { ekstremite } \\
\text { yerde } \\
\text { rotasyon }\end{array}$ & $\begin{array}{l}\text { Sırt üstü yatış pozisyonunda, kollar iki yana açılarak gövde stabilizasyonu sağlanarak } \\
\text { dizlerden } 90 \text { derece bükülü vaziyette sağ ve sola rotasyon yapılması. } 5 \text { saniye sağ ve } 5 \\
\text { saniye sola şeklinde ve } 10 \text { tekrarlı uygulama. }\end{array}$ \\
\hline $\begin{array}{l}\text { Bacaklarda } \\
\text { makas } \\
\text { hareketi }\end{array}$ & $\begin{array}{l}\text { Sırt üstü yatar pozisyonda bacaklar gergin vaziyette topukların yerden } 10 \mathrm{~cm} \text { yükseltilip } \\
\text { tekrar indirilerek her iki bacağın uygulanması. } 10 \text { tekrarlı uygulama. }\end{array}$ \\
\hline
\end{tabular}

Yıldız Uzan Eriş Denge Testi (Star Excursion Balance Test) (YUEDT) ve 60 saniye süre içerisinde iki ve üç sayı isabet skorlarının yüzdeleri için iki yönlü varyans analizi (two-way repeated measures of ANOVA) yapild1. 


\section{BULGULAR}

Çalışmaya 30 erkek sağlıklı sporcu katılmıştır. Deney grubunda yer alan 15 katılımcının boy değerleri 190,3 $\pm 8,17 \mathrm{~cm}$ ve vücut ağırlı̆̆ $88,3 \pm 8,13 \mathrm{~kg}$ iken kontrol grubunda yer alan 15 katılımcının boy değerleri ise $190,86 \pm 8,97 \mathrm{~cm}$ ve vücut ağırlı̆̆ $88,8 \pm 11,99 \mathrm{~kg}$ olarak tespit edilmiştir.

Tablo 2. Çalışmaya Katılan Deney ve Kontrol Grubu Sporcuların Yıldız Denge Testi Sol Ayakla Yapılan Denemelere Ait Tekrarlı Ölçümlerde İki Yönlü ANOVA Testi Sonuçları

\begin{tabular}{|c|c|c|c|c|c|}
\hline Değişkenler & & $\mathbf{N}$ & $\begin{array}{c}\text { Öntest } \\
(\text { Ortalama } \pm \text { Ss })\end{array}$ & Sontest (Ortalama \pm Ss) & $\begin{array}{c}\text { Grup X Zaman } \\
\text { (F) }\end{array}$ \\
\hline \multirow{2}{*}{$\begin{array}{l}\text { Anterior } \\
\text { Sol (cm) }\end{array}$} & Deney Grubu & 15 & $77.95 \pm 7,87$ & $80.89 \pm 8.84$ & \multirow{2}{*}{0,388} \\
\hline & Kontrol Grubu & 15 & $76.25 \pm 8.06$ & $78.04 \pm 7.61$ & \\
\hline \multirow{2}{*}{$\begin{array}{l}\text { Anterolateral } \\
\text { Sol }(\mathrm{cm})\end{array}$} & Deney Grubu & 15 & $90.40 \pm 8.40$ & $91.11 \pm 8.58$ & \multirow{2}{*}{0.109} \\
\hline & Kontrol Grubu & 15 & $84.89 \pm 8.35$ & $86.26 \pm 6.88$ & \\
\hline \multirow{2}{*}{$\begin{array}{l}\text { Lateral } \\
\text { Sol }(\mathrm{cm})\end{array}$} & Deney Grubu & 15 & $101.27 \pm 9.11$ & $107.60 \pm 10.85$ & \multirow{2}{*}{$4.927^{\star}$} \\
\hline & Kontrol Grubu & 15 & $94.82 \pm 8.68$ & $96.82 \pm 8.39$ & \\
\hline \multirow{2}{*}{$\begin{array}{l}\text { Posterolateral } \\
\text { Sol }(\mathrm{cm})\end{array}$} & Deney Grubu & 15 & $105.00 \pm 10.59$ & $111.82 \pm 10.53$ & \multirow{2}{*}{$10.698^{*}$} \\
\hline & Kontrol Grubu & 15 & $103.91 \pm 10.64$ & $105.44 \pm 10.58$ & \\
\hline \multirow{2}{*}{$\begin{array}{l}\text { Posterior } \\
\text { Sol }(\mathrm{cm})\end{array}$} & Deney Grubu & 15 & $103.85 \pm 9.95$ & $110.49 \pm 9.58$ & \multirow{2}{*}{$4.388^{*}$} \\
\hline & Kontrol Grubu & 15 & $105.53 \pm 10.60$ & $108.00 \pm 10.98$ & \\
\hline \multirow{2}{*}{$\begin{array}{l}\text { Posteromedial } \\
\text { Sol }(\mathrm{cm})\end{array}$} & Deney Grubu & 15 & $99.24 \pm 7.99$ & $107.93 \pm 10.51$ & \multirow{2}{*}{$12.324^{\star}$} \\
\hline & Kontrol Grubu & 15 & $100.49 \pm 11.89$ & $101.89 \pm 12.92$ & \\
\hline \multirow{2}{*}{$\begin{array}{l}\text { Medial } \\
\text { Sol }(\mathrm{cm})\end{array}$} & Deney Grubu & 15 & $84.93 \pm 7.36$ & $92.44 \pm 9.36$ & \multirow{2}{*}{$6.678^{\star}$} \\
\hline & Kontrol Grubu & 15 & $82.05 \pm 11.49$ & $83.82 \pm 12.90$ & \\
\hline \multirow{2}{*}{$\begin{array}{l}\text { Anteromedial } \\
\text { Sol }(\mathrm{cm})\end{array}$} & Deney Grubu & 15 & $71.51 \pm 5.44$ & $75.16 \pm 7.62$ & \multirow{2}{*}{$4.669^{\star}$} \\
\hline & Kontrol Grubu & 15 & $67.11 \pm 10.28$ & $1.96 \quad 9.41$ & \\
\hline
\end{tabular}

Çalışmaya katılan deney ve kontrol grubu sporcuların yıldız denge testi sol ayakla yapılan denemelere ilişkin ortalama ve standart sapma değerleri tablo 1'de gösterilmiştir. Yapılan tekrarlı ölçümler için iki yönlü varyans analizi (two-way repeated measures of ANOVA) sonucunda, deney ve kontrol grubu sporcularin ylldiz denge testine ait ylldı denge testi Lateral $(\mathrm{F}=4.927$; $\mathrm{p}<0.05)$, ylld $\mathrm{z}$ denge testi posterolateral $(\mathrm{F}=10.698 ; \mathrm{p}<0.05)$, ylld $\mathrm{z}$ denge testi posterior $(\mathrm{F}=4.388$; 
$\mathrm{p}<0.05)$, yıldız denge testi posteriormedial $(\mathrm{F}=12.324 ; \mathrm{p}<0.05)$, y1ldız denge testi medial $(\mathrm{F}=6.678$; $\mathrm{p}<0.05)$ ve yıldız denge testi anteromedial $(\mathrm{F}=4.669 ; \mathrm{p}<0.05)$ öntest ve sontest değerleri arasında GrupXZaman etkileşimi anlamlı bulunmuştur.

Tablo 3. Çalışmaya Katılan Deney ve Kontrol Grubu Sporcuların Yıldız Denge Testi Sağ Ayakla Yapılan Denemelere Ait Tekrarlı Ölçümlerde İki Yönlü ANOVA Testi Sonuçları

\begin{tabular}{|c|c|c|c|c|c|}
\hline Değişkenler & & $\mathbf{N}$ & $\begin{array}{c}\text { Öntest } \\
(\text { Ortalama } \pm S s)\end{array}$ & $\begin{array}{c}\text { Sontest } \\
(\text { Ortalama } \pm \text { Ss })\end{array}$ & $\begin{array}{c}\text { Grup X Zaman } \\
\text { (F) }\end{array}$ \\
\hline \multirow{2}{*}{$\begin{array}{l}\text { Anterior } \\
\text { Sağ }(\mathrm{cm})\end{array}$} & Deney Grubu & 15 & $76.80 \pm 6.87$ & $77.16 \pm 7.71$ & \multirow{2}{*}{0.563} \\
\hline & Kontrol Grubu & 15 & $77.18 \pm 7.12$ & $78.89 \pm 8.34$ & \\
\hline \multirow{2}{*}{$\begin{array}{l}\text { Anterolateral } \\
\text { Sağ }(\mathrm{cm})\end{array}$} & Deney Grubu & 15 & $89.93 \pm 6.63$ & $94.44 \pm 8.74$ & \multirow{2}{*}{2.560} \\
\hline & Kontrol Grubu & 15 & $86.73 \pm 8.17$ & $88.58 \pm 9.06$ & \\
\hline \multirow{2}{*}{$\begin{array}{l}\text { Lateral } \\
\text { Sağ }(\mathrm{cm})\end{array}$} & Deney Grubu & 15 & $100.56 \pm 7.84$ & $107.58 \pm 9.42$ & \multirow{2}{*}{3.881} \\
\hline & Kontrol Grubu & 15 & $95.31 \pm 8.04$ & $97.91 \pm 8.82$ & \\
\hline \multirow{2}{*}{$\begin{array}{l}\text { Posterolateral } \\
\text { Sağ }(\mathrm{cm})\end{array}$} & Deney Grubu & 15 & $103.91 \pm 7.52$ & $117.11 \pm 10.39$ & \multirow{2}{*}{$17.814^{\star}$} \\
\hline & Kontrol Grubu & 15 & $106.02 \pm 8.78$ & $105.47 \pm 11.48$ & \\
\hline \multirow{2}{*}{$\begin{array}{l}\text { Posterior } \\
\text { Sağ }(\mathrm{cm})\end{array}$} & Deney Grubu & 15 & $103.82 \pm 8.51$ & $113.80 \pm 11.18$ & \multirow{2}{*}{$7.757^{\star}$} \\
\hline & Kontrol Grubu & 15 & $106.04 \pm 9.30$ & $108.09 \pm 10.27$ & \\
\hline \multirow{2}{*}{$\begin{array}{l}\text { Posteromedial } \\
\text { Sağ }(\mathrm{cm})\end{array}$} & Deney Grubu & 15 & $97.00 \pm 7.87$ & $106.93 \pm 8.48$ & \multirow{2}{*}{$11.671^{\star}$} \\
\hline & Kontrol Grubu & 15 & $101.60 \pm 10.49$ & $104.38 \pm 8.54$ & \\
\hline \multirow{2}{*}{$\begin{array}{l}\text { Medial } \\
\text { Sağ }(\mathrm{cm})\end{array}$} & Deney Grubu & 15 & $84.60 \pm 9.49$ & $92.69 \pm 11.07$ & \multirow{2}{*}{$4.624^{*}$} \\
\hline & Kontrol Grubu & 15 & $83.24 \pm 12.53$ & $85.47 \pm 10.68$ & \\
\hline \multirow{2}{*}{$\begin{array}{l}\text { Anteromedial } \\
\text { Sağ }(\mathrm{cm})\end{array}$} & Deney Grubu & 15 & $70.11 \pm 5.59$ & $71.29 \pm 6.13$ & \multirow{2}{*}{0.499} \\
\hline & Kontrol Grubu & 15 & $68.64 \pm 8.74$ & 1.898 .79 & \\
\hline
\end{tabular}

Çalışmaya katılan deney ve kontrol grubu sporcuların yıldız denge testi să̆ ayakla yapılan denemelere ilişkin ortalama ve standart sapma değerleri tablo 2'de gösterilmiştir. Yapılan tekrarlı ölçümler için iki yönlü varyans analizi (two-way repeated measures of ANOVA) sonucunda, deney ve kontrol grubu sporcuların yıldız denge testine ait yıldız denge testi Posterolateral $(\mathrm{F}=17.814 ; \mathrm{p}<0.05)$, ylld $\mathrm{z}$ denge testi Posterior $(\mathrm{F}=7.757 ; \mathrm{p}<0.05)$, ylld $1 \mathrm{z}$ denge testi Posteromedial $(\mathrm{F}=11.671 ; \mathrm{p}<0.05)$ ve yıldız denge testi Medial $(\mathrm{F}=4.624 ; \mathrm{p}<0.05)$ öntest ve sontest değerleri arasında GrupXZaman etkileşimi anlamlı bulunmuştur. 
Tablo 4. Çalışmaya Katılan Deney ve Kontrol Grubu Sporcuların I Dakikada Kaydettiği Şut Yüzdelerine Ait Tekrarlı Ölçümlerde İki Yönlü ANOVA Testi Sonuçları

\begin{tabular}{lccccc}
\hline Değişkenler & N & $\begin{array}{c}\text { Öntest } \\
(\text { Ortalama } \pm \text { Ss })\end{array}$ & $\begin{array}{c}\text { Sontest } \\
(\text { Ortalama } \pm S s)\end{array}$ & $\begin{array}{c}\text { GrupXZaman } \\
(\text { F) }\end{array}$ \\
\hline $\begin{array}{l}1 \text { dakikada } \\
\text { İki Sayllı Şut }\end{array}$ & Deney Grubu & 15 & $25.83 \pm 8.65$ & $46.11 \pm 14.56$ & $43.130^{*}$ \\
$\begin{array}{l}\text { Yüzdesi (\%) } \\
1 \text { dakikada }\end{array}$ & Kontrol Grubu & 15 & $31.39 \pm 6.66$ & $33.61 \pm 6.95$ & \\
$\begin{array}{l}\text { Üç Sayllı Şut } \\
\text { Yüzdesi (\%) }\end{array}$ & Koney Grubu & 15 & $15.83 \pm 10.11$ & $34.72 \pm 13.33$ & $28.639^{*}$ \\
\hline
\end{tabular}

Çalışmaya katılan deney ve kontrol grubu sporcuların 1 Dakikada Kaydettiği Şut Yüzdelerine ilişkin ortalama ve standart sapma değerleri tablo 3'de gösterilmiştir. Yapılan tekrarlı ölçümler için iki yönlü varyans analizi (two-way repeated measures of ANOVA) sonucunda, deney ve kontrol grubu sporcuların 1 dakikada kaydettiği iki sayılık $(\mathrm{F}=43.130 ; \mathrm{p}<0.05)$ ve üç sayılık $(\mathrm{F}=28.639$; $\mathrm{p}<0.05)$ şu yüzdelerine ait öntest ve sontest değerleri arasında GrupXZaman etkileşimi anlamlı bulunmuştur.

\section{TARTIŞMA}

Basketbol branşında en önemli unsurlardan birisi de şuttur. İyi bir şutör bir takım fiziksel yeteneklere ehil olmalıdır (Uzun ve Pulur, 2011). Denge yeteneği de basketbolda şut atarken ve hareket ederken önemli bir unsurdur. İyi bir denge yeteneğine sahip olan sporcular vücutlarını kontrol edebilme kapasiteleri de yüksektir (Kostopoulos ve ark.,2012). Bu bağlamda düşünüldüğünde denge ile şut performansı arasında bir ilişkinin varlığından rahatlıkla söz edilebilir. Sportif aktivitelerde core denge oldukça önemli bir bileşendir (Sadeghi, Shariat, Asadmanesh ve Mosavat, 2013). Bu çalışmadaki birincil amacımız core antrenmanlar sonucunda denge performansının ve şut isabetlerinin gelişimlerini sağlamaktır.

Antrenman bilimindeki gelişmeler ile birlikte artan antrenman kalitesi performansa da yansıdığı düşünülmektedir. Temel motorik özelliklerin gelişimi teknik ve taktik olgularının uygulanmasını kolaylaştırdığı bilinmektedir (Mülazımoğlu, 2012). Alt ekstremite kuvvetinin dikey sıçrama yüksekliğine ve bu noktaya çıkma süresine dolayısıyla da şut performansına olumlu katkısı vardır (Struzik, Pietraszewski ve Zawadzki, 2014). Ayrıca şut, pas ve top sürme tekniklerinin de birbirlerine olumlu etkisi bulunmuştur (Brandao, Janeira, Cura ve Cura ,2003). Son dönemdeki bu gelişmeler ışı̆̆ında NBA saha içi isabet verileri maç başına incelendiğinde 2005 - 2006 sezonunda 35,8 olan ortalama 2015 - 2016 sezonunda 38,1 değerine yükseldiği gözlenmiştir. Ayrıca NBA üç sayı isabet oranları maç başına incelendiğinde 2005 - 2006 sezonunda 5,7 olan ortalama 2015 - 2016 sezonunda 8,4 noktasına geldiği tespit edilmiştir (http://stats.nba.com/league/team/\#!/ Erişim Tarihi: 30.06.2016 11: 32). Bizim çalışmamızda da 8 haftalık CA sonucunda hem 2 sayılık hem de 3 sayılık isabet sayılarında ön test son test ölçümleri arasında anlamlı artış gözlenmiştir. 
Çalışmamızın temel amacı basketbolcularda denge yeteneğinin 8 haftalık antrenmanlar sonrasında gelişim seviyesini göstermektir. Çalışmamızın sonuçlarına göre deney grubunun denge yeteneği değerleri hem sağ ayakta hem de sol ayakta kontrol grubuna göre gelişim göstermiştir. Bizim çalışmamıza benzer nitelikte McLeod ve arkadaşları 2009'da yaptıkları çalışmada 6 haftalık denge antrenmanlarının genç lisesi basketbolcu bayanlarda Yıldız Denge Testi ön test ve son test sonuçları arasında anlamlı değişimlere neden olduğu verisini ortaya koymuştur. McLeod ve arkadaşları bu çalışmalarında Lateral, Antero-medial, Medial ve Posterior düzlemde anlamlı farklılıklar bulmuşlardır (McLeod, Armstrong, Miller ve Sauers ,2009). Bizim çalışmamızda da Mcleod ve arkadaşlarının sonuçlarına benzer sonuçlar ortaya konmuştur. Sadeghia ve arkadaşları 2013'de yürüttükleri çalışmada düzenli olarak core antrenman yapan voleybolcuların ön test ve son test Yıldız Denge Testi sonuçları anlamlı bulunmuştur. Ayrıca Sedaghia ve arkadaşları da bizim sonuçlarımızla benzer olarak her iki ayakta da Posterior-Lateral, Posterior-Medial, Posterior ve Medial düzlemde istatistiksel açıdan anlamlı farklılık tespit etmişlerdir (Uzun ve Pulur,2011). Core antrenmanlarının denge performansı üzerine olumlu etkilerinin olduğuna dair Yıldız Denge Testi ölçümü ile tespit edilen çalışmalar mevcuttur (Herrington, Hatcher, Hatcher ve McNicholas, 2009), (Plisky, Rauh, Kaminski ve Underwood, 2006). Denge yeteneğinde sporcuların elde ettiği verimlilik performanslarında artışa sebebiyet vermektedir. Bressel ve arkadaşları 2007 yılında yaptıkları çalışmada dinamik denge ve performans arasında bir ilişkinin varlığından bahsetmişlerdir (Bressel, Yonker, Kras ve Keath,2007).

\section{SONUÇ}

Star Excursion Balance Test dinamik denge performansının tespiti noktasında oldukça sık olarak kullanılan bir testtir. Bizim çalışmamızda da sporcuların denge performanslarının Core antrenmanlara verdiği yanıtları ölçmek için Star Excursion Balance Test kullanılmıştır. Düzenli, yapılandırılmış ve planlı uygulanan Core antrenmanların basketbolcuların hem 2 ve 3 sayılık şut isabet oranlarını hem de dinamik denge verimliliklerini arttırdığı sonucuna varmak mümkündür. 


\section{KAYNAKLAR}

Kostopoulos N., Bekris E., Apostolidis N., Kavroulakis E., Kostopoulos P. (2012). The Effect Of A Balance And Proprioception Training Program On Amateur Basketball Players' Passing Skills. Journal of Physical Education and Sport, 12(3):316-323.

Boccolini G., Brazzit A., Bonfanti L., Alberti G. (2013). Using Balance Training To Improve The Performance Of Youth Basketball Players. Sport Sciences for Health, 9(2):37-42.

Kuşakoğlu Ö. (2012). Adölesan Dönemde Farklı Yaş Gruplarındaki Erkek Futbolcularda Çevikliğin Değerlendirilmesi. Fizyoterapi ve Rehabilitasyon Yüksek Lisans Programı, İstanbul Bilim Üniversitesi, İstanbul.

Uzun, A., Pulur, A. (2011). Genç Basketbolcularda (14-15 Yaş) Serbest Atış Antrenmanlarının Atış İsabet Oranı Gelişimine Etkisinin Araştııılması. Niğde Üniversitesi Beden Eğitimi ve Spor Bilimleri Dergisi, 5(2):81-89.

Sadeghi H., Shariat A., Asadmanesh E., Mosavat M. (2013). The Effects of Core Stability Exercise on the Dynamic Balance of Volleyball Players. International Journal of Applied Exercise Physiology, 2(2):1-10.

Mülazımoğlu O. (2012). Genç Basketbolcularda Yorgunluğun Şut Tekniğine Etkisi. Selçuk University Journal of Physical Education and Sport Science, 14(1):37-41.

Struzik A., Pietraszewski B., Zawadzki J. (2014). Biomechanical Analysis of the Jump Shot in Basketball. Journal of Human Kinetics, 42(1):73-79

Brandao E, Janeira M, Cura J, Cura P. (2003). Relationship Between Tecnical Skills and Game Performance in Youth Basketball Players. Revista Portuguessa De Ciencias De Desporto, 3(2):121-171.

http://stats.nba.com/league/team/\#!/ Erişim Tarihi: 30.06.2016 11: 32

McLeod T. C. V., Armstrong T., Miller M., Sauers J. L. (2009) Balance Improvements in Female High School Basketball Players After a 6-Week Neuromuscular-Training Program. Journal of Sport Rehabilitation, 18: 465-481.

Herrington, L., Hatcher, J., Hatcher, A., McNicholas, M. (2009). A comparison of Star Excursion Balance Test reach distances between ACL deficient patients and asymptomatic controls. The Knee, 16(2), 149-152.

Plisky, P., Rauh, M., Kaminski, T., Underwood, F. (2006). Star Excursion Balance Test As A Predictor Of Lower Extremity Injury in High School Basketball Players. The Journal of orthopaedic and sports physical therapy, 36(12), 9-11.

Santana, JC. (2005)Strength training for swimmers: Training the core. Clin J Sport Med,2(27), 40-42.

Atan, T., Kabadayı, M., Elioz, M., Cilhoroz, B. T., Akyol, P. (2013). Effect of Jogging and Core Training After Supramaximal Exercise on Recovery. Turkish Journal of Sport and Exercise, 15(1), 73-77.

Xibo S., Qian G., Honglei D., Shujie T. (2016). Which is Better in The Rehabilitation Of Stroke Patients, Core Stability Exercises or Conventional Exercises?, 28, 1131-1133.

Iacono, A. D., Martone D., Alfieri A., Ayalon M., Buono P. (2014). Core Stability Training Program (CSTP) Effects on Static and Dynamic Balance Abilities. Gazetta Medica Italiana, 173(4), 197-206.

Zech, A., Hübscher, M., Vogt, L. Banzer, W., Hansel, F., Pfeifer, K. (2010). Balance Training for Neuromuscular Control and Performance Enhancement: A Systematic Review. Journal of Athletic Training, 45(4), 392-403.

Kaushik, A., Sharma S. (2013). A Correlation Between Latency Period of Transverse Abdominis and Dynamic Balance: An EMG Study. Physiotherapy and Occupational Therapy Journal, 6(3),

Hibbs, A. E., Thompson K. G., French D. N., Hodgson D., Spears, I. E. (2011). Peak and Average Rectified EMG Measures: Which Method of Data Reduction Should be Used for Assessing core Training Exercises? Journal of Electromyography and Kinesiology, 21 102-111. 
Bressel, E., J.C. Yonker, J. Kras, and E.M. Keath. (2007). Comparison of Static and Dynamic Balance in Female Collegiate Soccer, Basketball, and Gymnastics Athletes. Journal of Athletic Training, 42(1), 42- 46.

Pojskić, H., Šeparović, V., Užičanin, E. (2011). Reliablity and Factorial Validity of Basketball Shooting Accuracy Tests. Sport SPA, 8(1), 25 - 32.

Gribble, P. A., Hertel J., Plisky, P. (2012). Using the Star Excursion Balance Test to Assess Dynamic Postural-Control Deficits and Outcomes in Lower Extremity Injury: A Literature and Systematic Review. Journal of Athletic Training, 47(3), 339 - 357.

Kahle, N., Tevald, M. A. (2014). Core Muscle Strengthening's Improvement of Balance Performance in Community-Dwelling Older Adults: A Pilot Study. Journal of Aging and Physical Activity, 22, $65-73$. 
